\title{
The use of botulinum toxin type $A$ in the treatment of HTLV-1-associated overactive bladder refractory to conventional therapy
}

\author{
José Abraão Carneiro Neto ${ }^{[1]}$, Valéria Gusmão Bittencourt ${ }^{[1]}$, Cassius de Oliveira ${ }^{[1]}$, \\ Rosana Andrade ${ }^{[1]}$ and Edgar Marcelino de Carvalho ${ }^{[1],[2]}$
}

[1]. Serviço de Imunologia, Hospital Universitário Prof. Edgard Santos, Universidade Federal da Bahia, Salvador, BA. [2]. Instituto Nacional de Ciência e Tecnologia de Doenças Tropicais, Ministério da Ciência e Tecnologia, Conselho Nacional de Desenvolvimento Científico e Tecnológico, Brasília, DF.

\begin{abstract}
Urinary symptoms occur in 19\% of human T-cell lymphotropic virus type 1 (HTLV-1)-infected patients who do not fulfill criteria for HTLV-1-associated myelopathy/tropical spastic paraparesis (HAM/TSP) and in almost 100\% of HAM/TSP patients. Few studies have evaluated therapies for overactive bladder (OAB) caused by HTLV-1 infection. This case report describes the effect of onabotulinum toxin A on the urinary manifestations of three patients with HAM/TSP and OAB symptoms. The patients were intravesically administered 200 units of Botox ${ }^{\circledR}$. Their incontinence episodes improved, and their OAB symptoms scores (OABSS) reduced significantly. These data indicate that Botox ${ }^{\circledR}$ should be a treatment option for OAB associated with HTLV-1 infection.
\end{abstract}

Keywords: HTLV-1. Overactive bladder. Botox.

\section{INTRODUCTION}

Human T-cell lymphotropic virus type 1 (HTLV-1) predominantly infects $\mathrm{T}$ cells and leads to a variety of clinical manifestations, the most important of which are HTLV-1associated myelopathy/tropical spastic paraparesis (HAM/TSP) and adult T-cell leukemia lymphoma (ATLL). HAM/TSP is characterized by back pain, leg weakness, hyperreflexia of the inferior limbs, Babinski sign, and difficulty in walking ${ }^{1}$. Urinary symptoms occur in up to $100 \%$ of patients with HAM/TSP, and overactive bladder $(\mathrm{OAB})$ is the main autosomatic manifestation of HAM/TSP ${ }^{2}$. The main findings of urodynamic studies in such patients are overactivity of the detrusor muscle followed by detrusor sphincter dyssynergia, but detrusor areflexia has been documented in a small percentage of cases $^{3}$.

While HAM/TSP occurs in less than $5 \%$ of HTLV-1infected subjects, OAB characterized by urgency and other urinary symptoms, such as nocturia and incontinence, occurs in up to $19 \%$ of HTLV-1-infected people who do not fulfill criteria for $\mathrm{HAM} / \mathrm{TSP}^{3}$. Moreover, the urinary symptoms of $\mathrm{OAB}$ may be the first manifestation of $\mathrm{HAM} / \mathrm{TSP}^{1,4}$. Urinary

\footnotetext{
Address to: Dr. José Abraão Carneiro Neto. Serviço de Imunologia/Complexo Hospitalar Universitário Prof. Edgard Santos/UFBA. R. Augusto Viana s/n, Canela, 40150-010 Salvador, BA, Brasil.

Phone 5571 3283-8114

e-mail: abraao.neto@gmail.com

Received 10 February 2014

Accepted 22 May 2014
}

manifestations are important complaints of HTLV-1-infected patients that decrease their quality of life and ability to work ${ }^{5,6}$. Some patients experience voiding dysfunction and underactivity of the detrusor or detrusor areflexia that requires intermittent self-catheterization ${ }^{6}$. The relationship between HTLV-1 infection and OAB is well documented. The expanded disability status scale (EDSS) has been used to evaluate the degree of neurologic dysfunction caused by HTLV-1, and a direct correlation between EDSS scores and urinary dysfunction has been revealed ${ }^{4}$. Moreover, pro-viral load and the production of pro-inflammatory cytokines that characterize HAM/TSP are also seem increased in patients with $\mathrm{OAB}$ without $\mathrm{HAM} / \mathrm{TSP}^{7,8}$. These data suggest that $\mathrm{OAB}$ is a common urologic finding of $\mathrm{HAM} / \mathrm{TSP}$ that may precedes full-blown HAM/TSP.

While the prevalence and relevance of urinary symptoms in cases of HTLV-1 infection are well documented, little research regarding treatment has been conducted. In our clinic, we have observed that only $50 \%$ of patients with HTLV-1-associated $\mathrm{OAB}$ exhibit improvements in symptoms upon treatment with propantheline bromide. Up to now, there's no study evaluating the effect of oxybutynin or another anticholinergic agent, much more selective for the bladder receptors, in these patients. A double-blind controlled study comparing propantheline bromide, placebo and oxybutynin in patients with overactive bladder without HTLV-1 did not reveal any significant difference between the group that received propantheline bromide and those that received placebo 9 . In another study, among 39 patients with HAM/TSP who had received pulse therapy with methylprednisolone, improvement in motor disability was observed in more than $60 \%$ of cases, but no improvements in bladder dysfunction were noted ${ }^{10}$. 
Botulinum toxin $\mathrm{A}$ is a neuromuscular blocking agent that can promote weakness in the detrusor sphincter muscle and control symptoms of $\mathrm{OAB}$, and has been used to treat idiopathic and neurogenic detrusor overactivity in patients with multiple sclerosis, spinal cord injury, and children with OAB due to myelomeningocele ${ }^{11,12}$. In a double-blind clinical trial of multiple sclerosis patients, botulinum toxin A was not only more effective than placebo, but $60 \%$ of the patients who had received botulinum toxin A had no urinary loss for up to 12 weeks ${ }^{11}$.

The aim of these case reports was to describe the effect of botulinum toxin A on the urinary manifestations of three patients with HTLV-1-associated OAB.

\section{CASE REPORT}

Demographic, clinical, urodynamic and cystoscopic data from three patients prior to botulinum toxin A treatment are given in Table 1.

Diagnosis of HTLV-1 infection was based on the detection of antibodies by enzyme-linked immunosorbent assay and confirmation by western blot. Moreover, all patients had HTLV-1 pro-viral loads detected in their peripheral blood mononuclear cells. All patients were female, and their ages ranged from 24 to 69 years. All patients had urinary complains for a long period. Patient 1 had nocturia and urgency for 10 years. Five years after her illness had started, she developed HAM/TSP. Voiding symptoms worsened, the post-voiding residual volume rose, and clean intermittent catheterization was introduced. The other two patients were admitted to the clinic after having HAM/ TSP for nine and 14 years, respectively. All patients had severe neurologic involvement with Osame scores (OMDS) greater than 5, and EDSS scores greater than 6. Detrusor overactivity was found in all three cases, and patients 1 and 3 also exhibited areflexia in urodynamic studies (Figure 1). All three patients had previously been treated with oxybutynin at a concentration of $10 \mathrm{mg}$ three times per day for at least two months with a poor response. Moreover, patients 1 and 3 had received oxybutynin by the intravesical administration route, which had failed to resolve symptoms in both cases.

This study was approved by the Ethical Committee of the Federal University of Bahia, and all patients signed an informed consent forms. The patients were asked to provide daily urinary reports before and after therapy, and were submitted to urodynamic examination prior to therapy. Additionally, each month after therapy, the patients completed a questionnaire about their urologic manifestations and neurologic complaints. Two hundred units of botulinum toxin $A$ (Botox ${ }^{\circledR}$, Allergan, Irvine, CA) were diluted in $30 \mathrm{~mL}$ of physiologic solution, and one $\mathrm{mL}$ of the solution was administered intravesically by cystoscopy in 30 different sites in the bladder. Urinary manifestations (frequency, nocturia, urgency, and incontinence), OAB scores (OABSS), bladder functional capacity, post-voiding residual volume, and duration of the response (time until the request of another treatment or return to previous OABSS) before and after onabotulinumtoxin type A administration are shown in Table 2.

After therapy, outpatient visits were scheduled at one week, two weeks, one month, and every two months thereafter. Improvements were observed in the first week and plateaued at one month. The information presented refers to the last visit after therapy. The data obtained were similar to the observations made after the first month of therapy. The most significant change observed was the disappearance of incontinence in all patients. The quality of life of the patients was greatly improved. With the exception of nocturia, which did not changed for patient 2, all other urinary manifestations either improved or disappeared. OABSS was also significantly reduced in all

TABLE 1 - Demographic and urologic findings from patients with HTLV-1-associated overactive bladder.

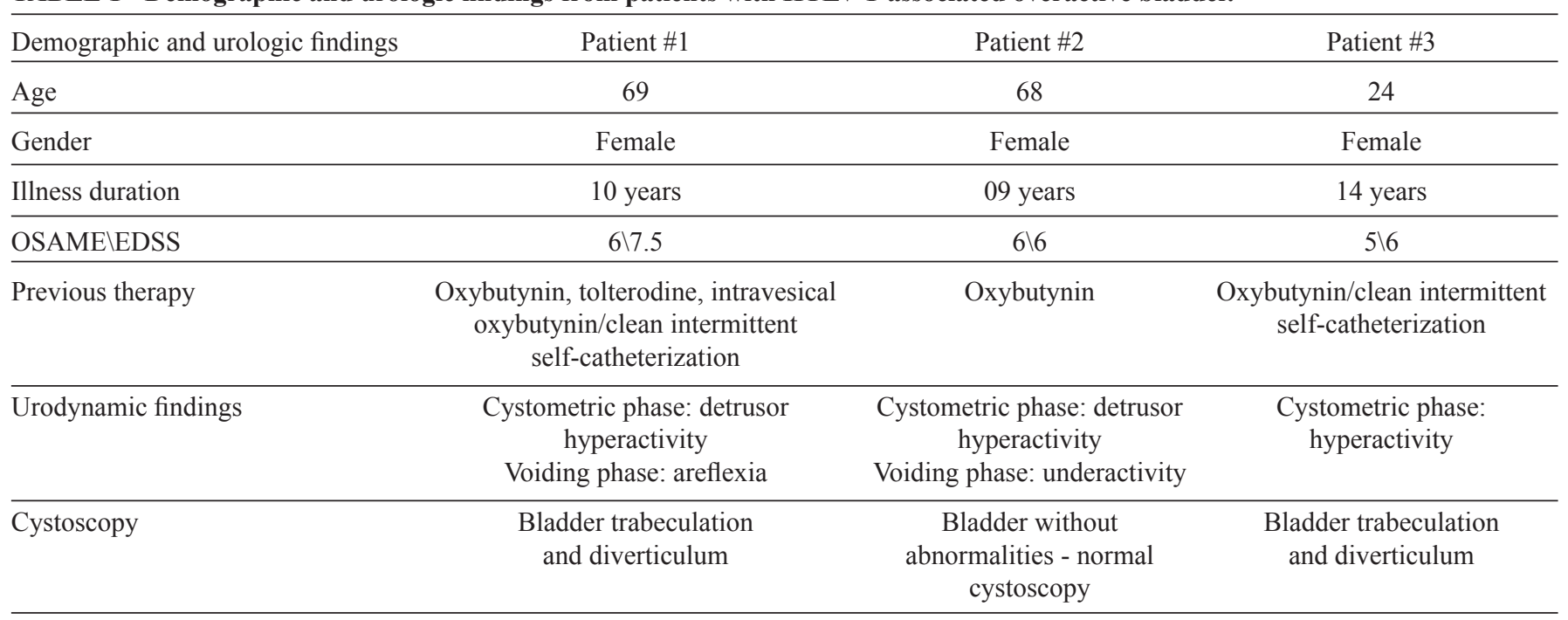

HTLV-1: human T-cell lymphotropic virus types 1; OSAME\EDSS: Osame scorelexpanded disability status scale. 
(A)

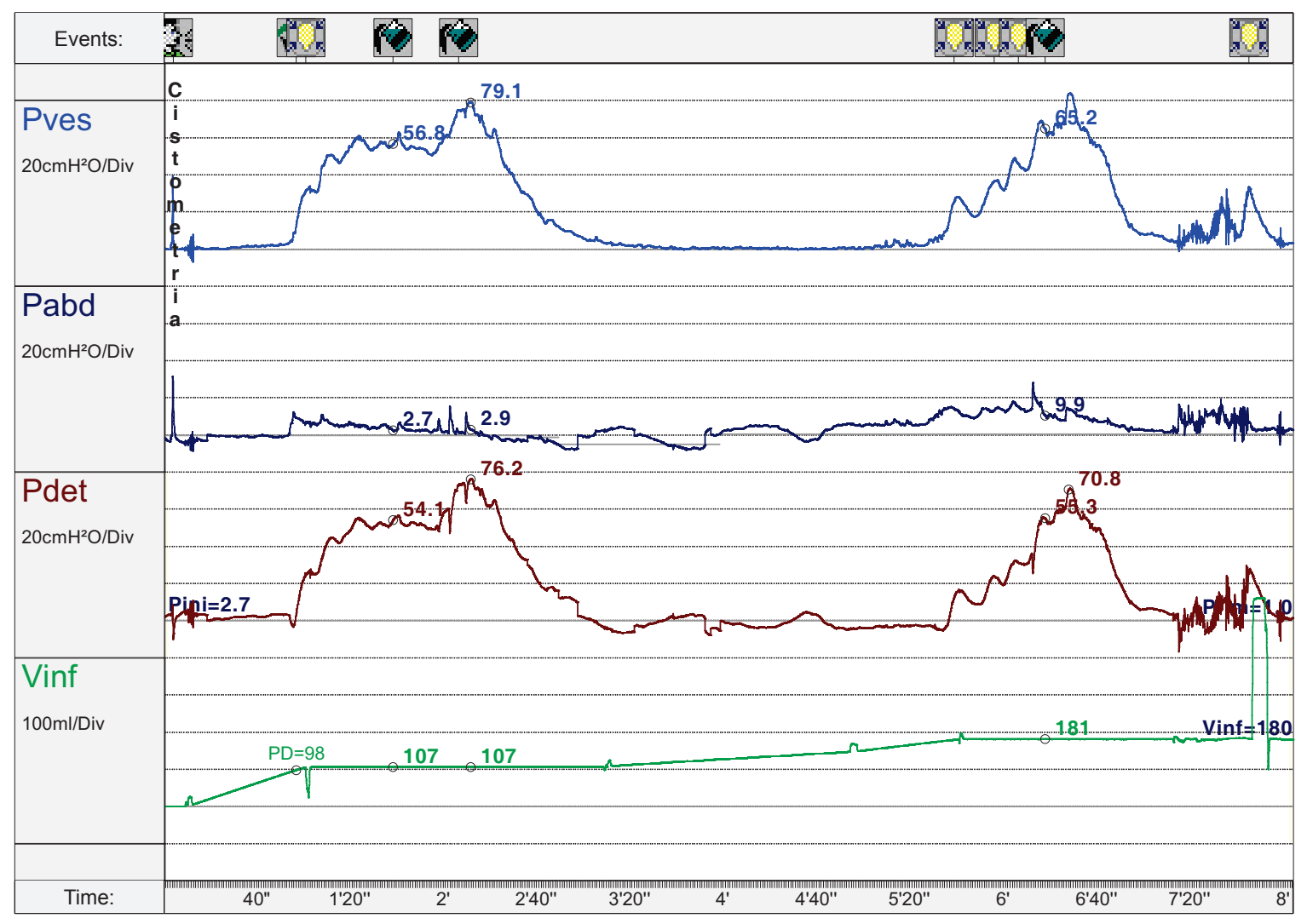

(B)

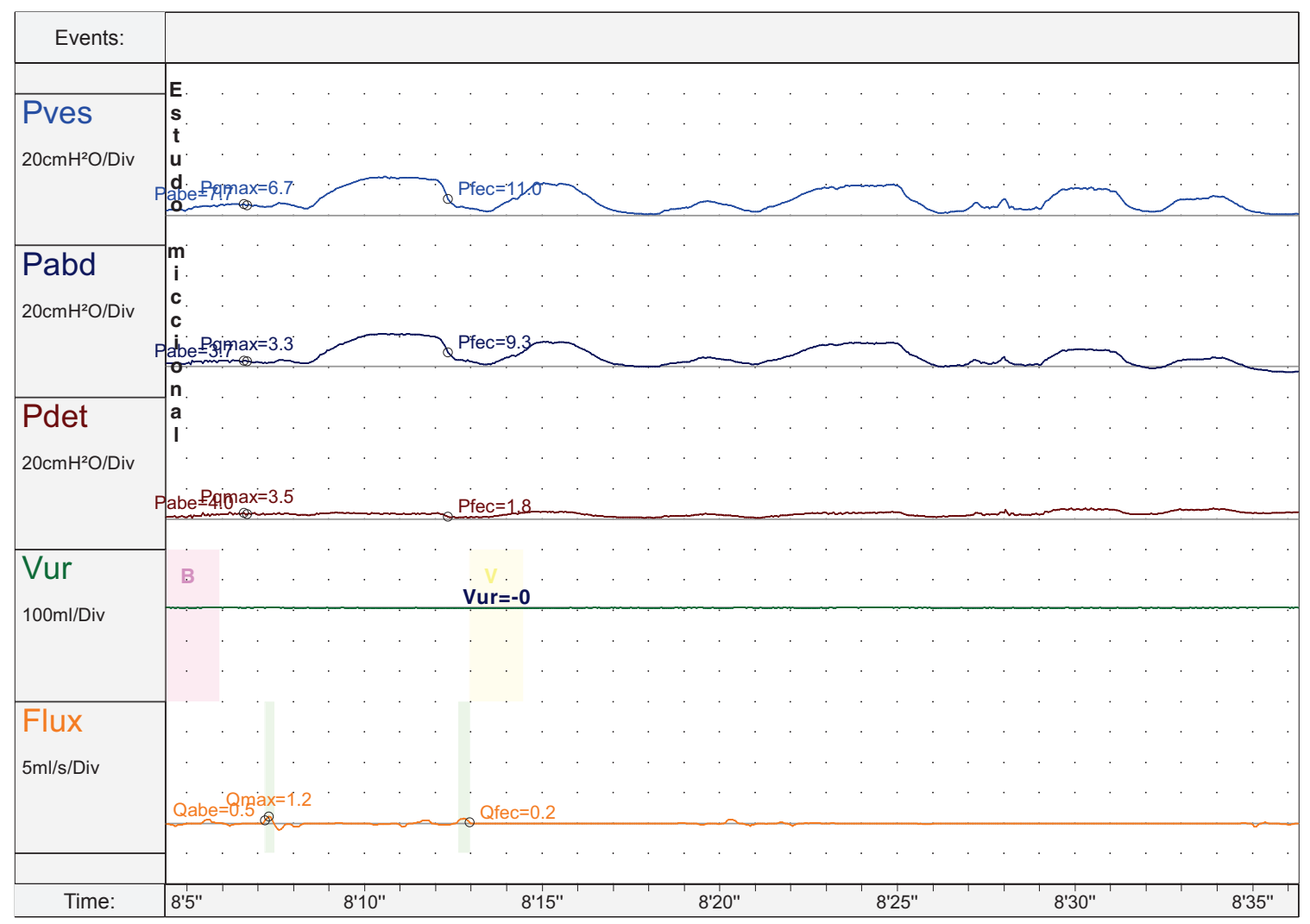

FIGURE 1 - Urodynamic study of patient 3: Detrusor hyperactivity on cystometry and detrusor areflexia in the voiding phase. A) Cystometry: Cystometry phase of the urodynamic study showing 2 detrusor involuntary contractions characterizing the overactive bladder; B) Pressure/flow phase (voiding): Voiding phase of the urodynamic study showing no voluntary detrusor contraction. 
TABLE 2 - Urologic manifestations before and after therapy with botulinum toxin.

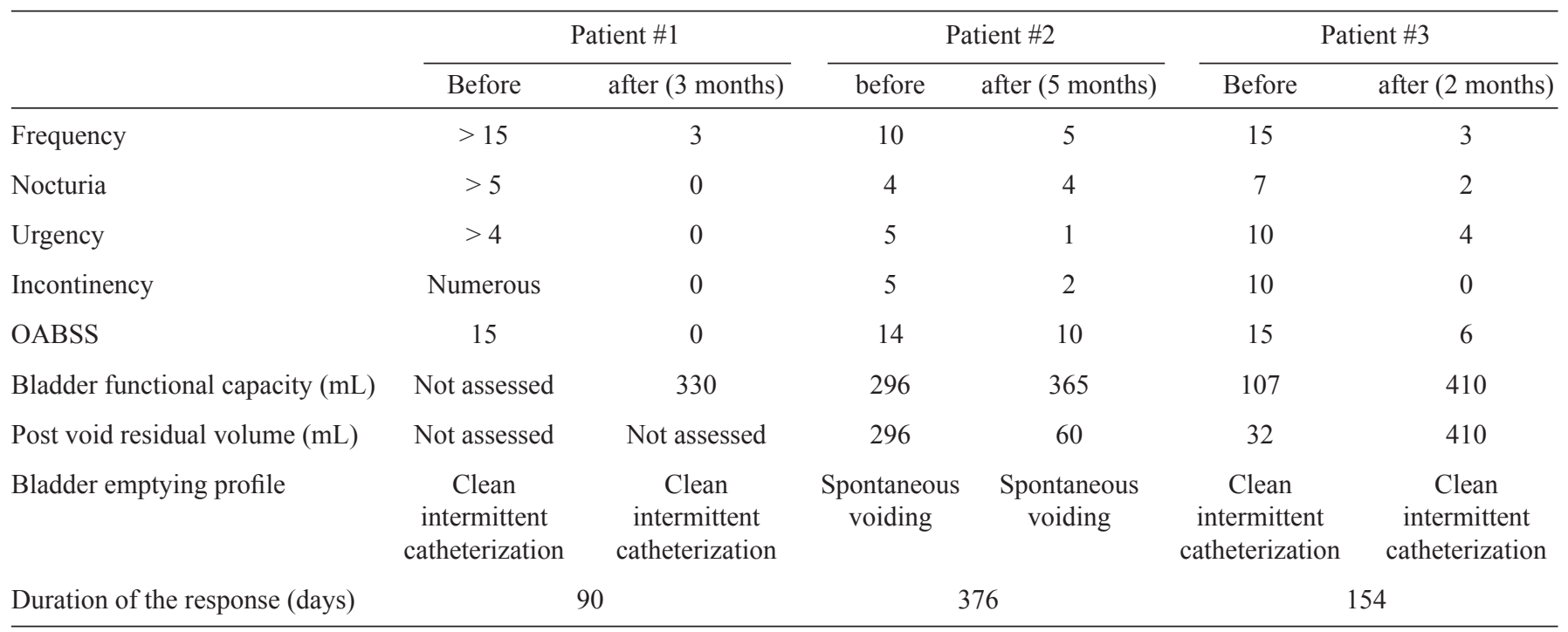

OABSS: overactive bladder symptom score.

patients. Prior to treatment, patient 3 used to have urinary loss of the entire urine volume of the bladder, suggesting a voiding pattern dependent on involuntary detrusor contraction. After the injection of botulinum toxin $\mathrm{A}$, the bladder could retain a physiologic amount of urine.

\section{DISCUSSION}

Urinary complains that are mainly due to $\mathrm{OAB}$ are highly relevant manifestations in HTLV-1 infection. In the present study, we showed that application of intravesical botulinum toxin $A$ at a dose of 200 units significantly improved the urinary manifestations of three patients with symptoms of OAB. The objective of treating $\mathrm{OAB}$ is to reduce episodes of urinary loss and preserve upper urinary tract function by reducing the intravesical pressure. Several treatments for OAB have been administered via oral and intravesical routes, but have not resulted in long-term clinical improvement. Botulinum toxin A has been studied as a potential treatment for $\mathrm{OAB}$, and although the sample size in the present study was somewhat limited, we could confirm these previous reports in the literature ${ }^{11}$ and demonstrate that botulinum toxin A could be a treatment choice for patients with HTLV-1-associated OAB that is refractory to conservative management.

The major indication of botulinum toxin $\mathrm{A}$ is for autonomic disorders such as muscle spasms. In such cases, patients usually need to use the drug every three months ${ }^{12}$. Therefore, we do not expect that a single application of botulinum toxin A will resolve for long-term urinary disorders related to HTLV-1 infection. However, the disappearance of some urinary symptoms and the significant improvement in OABSS scores that were maintained for up to five months provide support for future studies with a larger number of HTLV-1-infected patients.
In conclusion, onabotulinum toxin A was effective in controlling $\mathrm{OAB}$ symptoms for a significant duration with minimum side effects. Studies including a greater number of patients and longer follow-up periods should be performed to confirm these findings.

\section{ACKNOWLEDGMENTS}

We acknowledge Cristiano Franco for his help in the preparation of this manuscript.

\section{FINANCIAL SUPPORT}

Brazilian National Research Council CNPq - (Conselho Nacional de Desenvolvimento Científico e Tecnológico).

\section{REFERENCES}

1. Silva MT, Coutinho F, Leite AC, Harab RC, Araujo A, Andrada-Serpa MJ. Isolated bladder dysfunction in human $\mathrm{T}$ lymphotropic virus type 1 infection. Clin Infect Dis 2009; 48:34-36.

2. Oliveira P, Castro NM, Carvalho EM. Urinary and sexual manifestations of patients infected by HTLV-I. Clinics 2007; 62:191-196.

3. Castro NM, Freitas DM, Rodrigues Jr W, Muniz A, Oliveira P, Carvalho EM. Urodynamic features of the voiding dysfunction in HTLV-1 infected individuals. Int Braz J Urol 2007; 33:238-244.

4. Oliveira P, Castro NM, Muniz AL, Tanajura D, Brandao JC, Porto AF, et al. Prevalence of erectile dysfunction in HTLV-1-infected patients and its association with overactive bladder. Urology 2010; 75:1100-1103.

5. Castro NM, Rodrigues Jr W, Freitas DM, Muniz A, Oliveira P, Carvalho EM. Urinary symptoms associated with human T-cell lymphotropic virus type I infection: evidence of urinary manifestations in large group of HTLV-I carriers. Urology 2007; 69:813-818.

6. Diniz MS, Feldner PC, Castro RA, Sartori MG, Girao MJ. Impact of HTLV-I in quality of life and urogynecologic parameters of women 
with urinary incontinence. Eur J Obstet Gynecol Reprod Biol 2009; 147:230-233.

7. Santos SB, Porto AF, Muniz AL, Jesus AR, Magalhaes E, Melo A, et al. Exacerbated inflammatory cellular immune response characteristics of HAM/TSP is observed in a large proportion of HTLV-I asymptomatic carriers. BMC Infect Dis 2004;4:7.

8. Costa DT, Santos AL, Castro NM, Siqueira IC, Carvalho Filho EM, Glesby MJ. Neurological symptoms and signs in HTLV-1 patients with overactive bladder syndrome. Arq Neuropsiquiatr 2012; 70 : 252-256.

9. Thuroff JW, Bunke B, Ebner A, Faber P, Geeter P, Hannappel J, et al. Randomized, double-blind, multicenter trial on treatment of frequency, urgency and incontinence related to detrusor hyperactivity: oxybutynin versus propantheline versus placebo. J Urol 1991; 145:813-816.

10. Croda MG, Oliveira AC, Vergara MP, Bonasser F, Smid J, Duarte AJ, et al. Corticosteroid therapy in TSP/HAM patients: the results from a 10 years open cohort. J Neurol Sci 2008; 269:133-137.

11. Cruz F, Herschorn S, Aliotta P, Brin M, Thompson C, Lam W, et al. Efficacy and safety of onabotulinumtoxinA in patients with urinary incontinence due to neurogenic detrusor overactivity: a randomised, double-blind, placebo-controlled trial. Eur Urol 2011; 60:742-750.

12. Dressler D, Tacik P, Adib Saberi F. Botulinum toxin therapy of cervical dystonia: comparing onabotulinumtoxinA (Botox ${ }^{\circledR}$ ) and incobotulinumtoxin A (Xeomin $\left.{ }^{\circledR}\right)$. J Neural Transm 2013; 121:29-31 